\title{
Bioactive compounds and the antioxidant capacities of seed oils from pomegranate (Punica granatum L.) and bitter gourd (Momordica charantia L.)
}

\author{
Luciana Tedesco YOSHIME ${ }^{1}$, Illana Louise Pereira de MELO ${ }^{1}$, José Augusto Gasparotto SATTLER ${ }^{1}$, \\ Rosângela Pavan TORRES ${ }^{1}$, Jorge MANCINI-FILHO ${ }^{1 *}$
}

\begin{abstract}
Pomegranate and bitter gourd are two of the few edible fruits that contain conjugated $\alpha$-linolenic acids (CLnAs) in their seeds. The CLnAs have been associated with many effects that are beneficial to health, such as antioxidant and anti-inflammatory properties. Samples of cold-pressed oils from pomegranate and bitter gourd seeds were evaluated for their phytochemical compositions (fatty acids, tocopherols and phytosterols), their qualities and their stability parameters. The in vitro antioxidant capacities of these oils were evaluated by $\beta$-carotene bleaching, DPPH• scavenging, oxygen radical absorbance capacity (ORAC) and ABTS. scavenging assays. Several differences in the compositions of the fatty acids, the bioactive compounds and the antioxidant capacities were observed for the two seed oils (pomegranate and bitter gourd) when they were assessed. The highest contents for the phytochemicals (conjugated $\alpha$-linolenic acids, $\beta$-sitosterols, $\gamma$-tocopherols) and the in vitro antioxidant capacities were found in the pomegranate seed oil, when using both the DPPH• and ABTS• methods. These results have indicated that seed oils with bioactivity properties can be a challenge for more research, in order to address absorption, health benefits and technological applications.
\end{abstract}

Keywords: punicic acid; $\alpha$-eleostearic acid, phytosterols; tocopherols; antioxidant properties.

Practical Application: The researched results of these seed oils are important for the development of functional foods.

\section{Introduction}

The food industry generates by-products every year, while at the same time, wasting peels and seeds from fruits and vegetables. Recently, research studies have supported a potential source of oil from these waste seeds that are displaying beneficial and healthy attributes, like pomegranate (Punica granatum $\mathrm{L}$.) and bitter gourd (Momordica charantia L.). These seeds have also been gaining much attention due to their lipid contents, polyunsaturated fatty acids (PUFAs) and other bioactive compounds (for instance, the phytosterols and the tocopherols) (Jing et al., 2012; Fernandes et al., 2015; Aruna et al., 2016). Although almost all of the oils from plants contain PUFAs in the cis conformation, some contain one or more double bonds in their trans configuration. In addition, the physicochemical, nutritional, biochemical and biological properties differ between them (Mekni et al., 2014).

Recent findings on these oils have been related to their chemical and physiological properties, thus, increasing an interest in the conjugated $\alpha$-linolenic acids (CLnAs) and their isomers. The CLnAs refer to a group of positional and geometric isomers of the octadecatrienoic fatty acids that contain three conjugated double bonds, while some of them are in trans configurations (Melo et al., 2014). As a result, scientific interest has become increasingly attracted, mainly because of their many potential health benefits, including their antioxidant, anti-inflammatory, anti-atherosclerotic, antitumor and serum lipid-lowering activities, both in vitro and in vivo (Melo et al., 2014; Yuan et al., 2014; Hennessy et al., 2011). Moreover, their effectiveness varies substantially between the individual isomers.

Pomegranates (Punica granatum L.) and bitter gourds (Momordica charantia L.) are cultivated throughout the world, in particular, in the Mediterranean areas (Lucci et al., 2015; Saha et al., 2012). Recent studies have found that pomegranate seed oil (PSO) and bitter gourd seed oil (BSO) consist of 65\%-80\% punicic acid (PA; C18:3-9c,11t,13c) (Aruna et al., 2016; Parashar et al., 2010; Arora \& Chaudhary, 2012) and 30\%-60\% $\alpha$-eleostearic acid (EA; C18:3-9c,11t,13t) (Aruna et al., 2016; Saha et al., 2012; Khoddami et al., 2014), respectively, with both oils comprising amounts of the CLnAs. Structurally, PA and EA are long-chain PUFAs $(\omega-5)$. The only difference between EA and PA is the geometric structure of the double bond. This is since EA contains a trans double bond at position 13, while PA contains a cis double bond at this same position.

The recent growing interest in cold-pressed plant oils is due to their nutritional potentials, as well as with the high demands from consumers for functional foods that contain health-promoting compounds. A cold press extraction is a rapid mechanical process that does not require the use of organic solvents. Furthermore, it allows for a preservation of the characteristics 
and the numerous valuable compounds that display antioxidant properties, such as the tocopherols, the carotenoids, the sterols and the phospholipids (Khoddami et al., 2014; Sielicka et al., 2014; Prescha et al., 2014).

These antioxidant potentials are due to the action of a substance that is capable of protecting the biological systems from adverse reactions, which are caused by the excessive oxidation-induced reactive oxygen species (ROS). Hence, the determinations of the antioxidative capacities are used to characterize the health-promoting properties of the various products from a plant origin that contain natural antioxidants. They can reduce many degenerative processes and/or diseases which are related to oxidative stress - either as an etiological factor, or from a consequence of diseases that have an increasing incidence of harm in Western societies (Lucci et al., 2015; Anjum et al., 2013; Christie et al., 2001).

Previous studies with the CLnA isomers have shown that they play an important role in improving oxidative stress, especially when it is associated with clinical conditions and chronic diseases. Saha et al. (2012) have investigated the antioxidant activities of PA and EA in vegetable oils. They both exerted antioxidant activities at low concentrations, due to their better oxidative stabilities. In addition, bitter gourd showed a notable antioxidant activity, due to the presence of its higher trans content (Yuan et al., 2014; Saha et al., 2012). Many varying factors can generate these differences, particularly their origins and the methods that were used for their extraction (Fernandes et al., 2015; Saha et al., 2012; Sielicka et al., 2014; Prescha et al., 2014; Anjum et al., 2013).

Despite there being some studies about the biological and antioxidant activities of these seed oils, there is still a divergence in the literature data. Therefore, the aim of this study was to evaluate the phytochemical compositions and the in vitro antioxidant activities of cold-pressed oils, when they were obtained from pomegranate and bitter gourd seeds, with both of them containing conjugated $\alpha$-linolenic acid.

\section{Materials and methods}

\subsection{Samples and chemicals}

The pomegranate seed oil (PSO) and the bitter gourd seed oil (BSO) cold pressings were obtained from Green Source Organics (Boynton Beach, USA) and Health \& Beauty Natural Oils (Santa Barbara, CA), respectively. A linseed oil (LSO) sample was provided by Vital Âtman (Uchôa, Brazil), which was also obtained by cold pressing and this oil was used for the comparisons.

All of the products, namely, the fatty acid methyl esters (FAME-C4:24), the tocopherols ( $\alpha-, \beta-, \gamma-, \delta$-tocopherol), the phytosterols (campesterol, stigmasterol, $\beta$-sitosterol), $5 \alpha$-cholestane, $\beta$-carotene, the linoleic acid standards, sodium methoxide $(\mathrm{NaOCH} 3)$, the Tween 40 reagents, $\mathrm{DPPH} \bullet$ (2,2-diphenyl-1-picryhydrazyl radical), BHT (Butylated hydroxytoluene), AAPH [2,2'-Azo-bis(2-amidinopropane) dihydrochloride], the fluorescein disodium salt, Trolox (6-hydroxy-2,5,7,8- tetramethyl chroman-2-carboxylic acid), TBA (2-thiobarbituric acid) and ABTS [2,20-azinobis (3-ethylbenzothiazoline-6-sulfonic acid) diammonium salt], were all purchased from Sigma-Aldrich (St. Louis, MO, USA). The ultrapure water, which was prepared by a Millipore Simplicity ${ }^{B}$ water purification system (Darmastadt, Germany), was used in all of the experiments. All the other chemicals and solvents were of an analytical grade and they were purchased from Merck (Darmastadt, Germany) and Synth (Diadema, SP, Brazil).

\subsection{Chemical compositions}

\subsubsection{Fatty acid profile}

The fatty acids from the oils were transformed into methyl esters, in accordance with the alkaline esterification method, as proposed by Christie and others 2001, when using $\mathrm{NaOCH} 3$ in methanol. The extracts were then injected into the gas chromatography (Shimadzu ${ }^{\circledR}$ GC-2010) instrument, which had a flame ionization detector and a fused silica column (100 $\mathrm{m}$ and $0.25 \mathrm{~mm}$ internal diameter/SP-2560), following the schedule as described by Baublits et al. (2007). The identifications of the fatty acids were based upon a comparison of the retention times by using the Methyl Esters Mix Standard (C4-C24) (Sigma 18919). The retention times of the conjugated fatty acids were compared to these standards and they were identified in accordance with what has been presented in the literature. The results were expressed as percentages of the total fatty acids. The fatty acids that were present in the samples were confirmed by gas chromatography, coupled with mass spectrometry (GC-MS), when using Shimadzu QP5050A equipment. The samples were run on a GC application (fused silica capillary column Supelco SP-2560, $100 \mathrm{~m}, 0.25 \mathrm{~mm}, 0.2 \mu \mathrm{m}$ film thickness) and a GC/MS application (fused silica capillary column Elite-WAZ Polyethylene Glycol (PEG), $30 \mathrm{~m}, 0.25 \mathrm{~mm}, 0.55 \mu \mathrm{m}$ film thickness). The temperature gradients were as follows: $60^{\circ} \mathrm{C}$ for $1 \mathrm{~min}, 60^{\circ} \mathrm{C}-280^{\circ} \mathrm{C}$ at $5^{\circ} \mathrm{C} / \mathrm{min}$ intervals and $280^{\circ} \mathrm{C}$ for $10 \mathrm{~min}$. Both of the injector and the detector temperatures were $280^{\circ} \mathrm{C}$. Helium (column flow of $1.6 \mathrm{~mL} / \mathrm{min}$ ) was used as the carrier gas; the split ratio was 16 and the program time was $55 \mathrm{~min}$.

\subsubsection{Tocopherol content}

The determinations of the tocopherol contents were performed as recommended by Fernandes et al. (2015), with minor modifications. An aliquot of each oil was diluted with hexane; it was then filtered through a $0.22 \mu \mathrm{M}$ membrane and injected into the Shimadzu chromatograph instrument. The high-performance liquid chromatography (HPLC) system consisted of an autosampler and a fluorescence detector (RF-10AXL) (excitation: $295 \mathrm{~nm}$, emission: $330 \mathrm{~nm}$ ). The samples were run under isocratic conditions on a Shim-pack CLC-SIL column $(25 \mathrm{~cm}, 4.6 \mathrm{~mm}, 5 \mu \mathrm{m}$, Shimadzu) at a flow rate of $1.0 \mathrm{~mL} / \mathrm{min}$, with a pre-filtered and degassed mobile phase of hexane and isopropyl alcohol (99:1). The identifications of $\alpha-, \beta-, \gamma$ - and $\delta$-tocopherol were based upon the retention times and the quantifications were performed by an external standardization. The results were expressed as an $\mathrm{mg}$ of tocopherol per $100 \mathrm{~g}$ of oil. 


\subsubsection{Phytosterol content}

The determinations of the phytosterol contents were carried out in three steps, as recommended by Almeida (2009). They were as follows: a heat saponification when using $3 \% \mathrm{KOH}$ in a water bath at $50{ }^{\circ} \mathrm{C}$ under continuous stirring for three hours; an extraction of the unsaponifiable fraction in hexane $(10 \mathrm{~mL})$ under vortex mixing for one minute; and a quantification of the phytosterols by a gas chromatography (GC) instrument. This system consisted of a Shimadzu GC-2010 chromatograph that was equipped with a DB-5 poly (methylphenyil) siloxane column ( $5 \%$ phenyl, $60 \mathrm{~m}, 0.25 \mathrm{~mm}$ ) and a flame ionization detector. The temperature gradients were as follows: $150{ }^{\circ} \mathrm{C}$ for $0.1 \mathrm{~min}, 150^{\circ} \mathrm{C}-300^{\circ} \mathrm{C}$ at $10^{\circ} \mathrm{C}$ intervals for $1 \mathrm{~min}$ and $300^{\circ} \mathrm{C}$ for $10 \mathrm{~min}$. The temperatures of the injector and the detector were $250^{\circ} \mathrm{C}$ and $300^{\circ} \mathrm{C}$, respectively. Helium $(1 \mathrm{~mL} / \mathrm{min})$ was used as the carrier gas and the split ratio (the amount of sample entering the column) was 1:50. The identifications of the peaks were performed by comparing the retention times with those of the Sigma Standards (campesterol - C5157, stigmasterol - S6126 and $\beta$-sitosterol - S9889). The quantifications were performed by an internal standardization, when using $5 \alpha$-cholestane (Sigma C8003). The results were expressed as an $\mathrm{mg}$ of phytosterols per $100 \mathrm{~g}$ of oil.

\subsubsection{Total carotenoid content}

The determinations of the total carotenoid contents were conducted by a spectrophotometer (Spectronic ${ }^{\mathrm{mm}}$ GENESYS $^{\mathrm{mm}} 20$, Spectronic Instruments, Rochester, USA), when using hexane as the solvent at $450 \mathrm{~nm}$, as described by Ribeiro et al. (2012). The calculations of the carotenoid levels were performed by using the following formula: total carotenoids $(\mathrm{mg} / 100 \mathrm{~g})=\left(\mathrm{A}_{450} \times 100 \times \mathrm{V}\right) \div(250 \times \mathrm{L} \times \mathrm{W})$, where $A_{450}$ was the absorbance value at $450 \mathrm{~nm}$; $V$ was the solvent volume; L was the length of the light path expressed in centimeters; W was the sample mass (g); and 250 referred to the extinction coefficients. The results were expressed as a $\mu \mathrm{g}$ of carotenoids per gram $(\mu \mathrm{g} / \mathrm{g})$ of oil.

\subsection{Antioxidant capacities}

\subsection{1 $\beta$-carotene bleaching assays}

The $\beta$-carotene bleaching assays (a coupled oxidation of $\beta$-carotene/linoleic acid) were performed as described by Schubert et al. (1999). They monitored the oxidations (discoloration) of the $\beta$-carotene emulsions when using a spectrophotometer. Briefly, $0.2 \mathrm{~mL}$ of $\beta$-carotene/chloroform $(10 \mathrm{mg} / 10 \mathrm{~mL})$ solution, $20 \mu \mathrm{L}$ of linoleic acid and $0.5 \mathrm{~mL}$ of Tween-40 (emulsifier) were mixed until homogenization and the chloroform was then evaporated under N2. Subsequently, $50 \mathrm{~mL}$ of water was added and the mixture was vigorously shaken to produce a clear $\beta$-carotene/linoleic acid emulsion its absorbance at $470 \mathrm{~nm}$ was between 0.6 and 0.7 . In order to determine the antioxidant activities of the oil samples, $5 \mathrm{~mL}$ aliquots of the emulsion and $2 \mathrm{~mL}$ samples of the oil, which were diluted in ethanol $(3.5 \mathrm{mg} / 10 \mathrm{~mL})$, were mixed and kept in a water bath at $50^{\circ} \mathrm{C}$. Butylated hydroxytoluene (BHT) was used as a reference standard at the same concentrations and this was added to the samples. The absorbances were read at
$470 \mathrm{~nm}$ by a spectrophotometer (Spectronic ${ }^{\mathrm{Tm}}$ GENESYS $^{\mathrm{mm}} 20$, Spectronic Instruments, Rochester, USA), every 15 min over a period of $120 \mathrm{~min}$. The results were expressed by an absorbance decay curve, with respect to time.

\subsubsection{DPPH• scavenging assay}

The analyses of DPPH• scavenging were conducted as described by Blois (1958), with some adjustments. These methods were based on a decrease in the absorbance of $\mathrm{DPPH} \bullet$ (2,2-diphenyl-1-picrylhydrazyl free radical), when it was reduced by an antioxidant, a hydrogen donor. Briefly, the samples of the oils were diluted in n-butanol to different concentrations. A $0.5 \mathrm{~mL}$ aliquot of each concentration was then mixed with $1.5 \mathrm{~mL}$ of DPPH• in butanol $(3.0 \mathrm{mg} / 200 \mathrm{~mL})$, in order to initiate the reaction. After 30 minutes, the absorbances were measured at $517 \mathrm{~nm}$, when using a spectrophotometer (Spectronic ${ }^{\mathrm{mm}}$ GENESYS $^{\mathrm{rm}} 20$, Spectronic Instruments, Rochester, USA). The DPPH solution (without the samples) was used as control and BHT was used as a synthetic antioxidant for the comparisons. The DPPH• scavenging activities of the samples were expressed as follows: scavenging $\operatorname{activity}(\%)=\left(\mathrm{Abs}_{\text {control }}-\mathrm{Abs}_{\text {sample }}\right) \div \mathrm{Abs}_{\text {control }}$, where Abs control $_{\text {was }}$ the absorbance of the control and $\mathrm{Abs}_{\text {sample }}$ was the absorbance of the sample. The results were expressed by an inhibition percentage curve, with respect to the concentrations $(\mathrm{mg} / \mathrm{mL})$. The amount of antioxidant that was needed to reduce the $\mathrm{DPPH} \bullet$ concentrations by $50 \%$ (EC50) were then calculated.

\subsubsection{Oxygen Radical Absorbance Capacity (ORAC) assay}

The ORAC assays were conducted according to the method of Prior and co-workers (2003), with minor modifications. In brief, the samples were dissolved in acetone which contained $7 \% \beta$-cyclodextrin and the lipophilic antioxidant capacities were measured by using a Synergy H1 Multi-Mode Reader (Winooski, VT, USA); this was a fluorescence plate reader. AAPH, which is a water-soluble azo compound, was used as a peroxyl radical generator. Trolox was used as a synthetic antioxidant, in order to make a standard curve and fluorescein was used as a fluorescent probe. The procedures to measure the ORAC assays were as follows: $25 \mu \mathrm{L}$ of a blank (7\% $\beta$-cyclodextrin solution), or a Trolox standard, or the diluted samples, were mixed with $250 \mu \mathrm{L}$ of fluorescein $(40 \mathrm{nM})$ and incubated for $10 \mathrm{~min}$ at $37^{\circ} \mathrm{C}$, before the automatic injections of $25 \mu \mathrm{L}$ of the AAPH solution (153 nM). The fluorescence was measured every minute for $50 \mathrm{~min}$. Fluorescence filters were used at an excitation wavelength of $485 \mathrm{~nm}$ and at an emission wavelength of $520 \mathrm{~nm}$. The results were expressed by an inhibition percentage curve, with respect to the concentrations $(\mathrm{mg} / \mathrm{mL})$. The EC50 was then calculated.

\subsubsection{ABTS• scavenging assay}

The analyses of ABTS• scavenging were conducted as described by Nenadis and co-workers (2004), with some adjustments. These methods were based on a decrease in the absorbance of ABTS• (2,20-azinobis (3-ethylbenzothiazoline-6-sulfonic acid) diammonium salt-free radical), when it was reduced by an antioxidant, a hydrogen donor. Briefly, the samples of the oils were diluted in acetone/methanol (70/30) to different concentrations. 
A $0.5 \mathrm{~mL}$ aliquot of each concentration was then mixed with $1.5 \mathrm{~mL}$ of ABTS• in ethanol (with an initial absorbance 0.7 ), in order to initiate the reaction. After $6 \mathrm{~min}$, the absorbances were measured at $734 \mathrm{~nm}$, when using a spectrophotometer (Spectronic $^{\text {mit }}$ GENESYS $^{\text {mi }} 20$, Spectronic Instruments, Rochester, USA). Methanol was used as a blank and BHT was used as a synthetic antioxidant for the comparisons. The ABTS• scavenging activities of the samples were expressed as follows: scavenging $\operatorname{activity}(\%)=\left(\mathrm{Abs}_{\text {blank }}-\mathrm{Abs}_{\text {sample }}\right) \div \mathrm{Abs}_{\text {blank }}$, where $\mathrm{Abs}_{\text {blank }}$ was the absorbance of the control and Abs sample was the absorbance of the sample. The results were expressed by an inhibition percentage curve, with respect to the concentrations $(\mathrm{mg} / \mathrm{mL})$. The EC50 was then calculated.

\subsection{Quality and stability parameters}

The quality parameters of the oils, such as the acidity values (Av), the peroxide values ( $\mathrm{Pv})$ and the 2-thiobarbituric acid values (TBAv) were evaluated, when using the classical methods, as described by American Oil Chemists' Society (2004). The Rancimat ${ }^{\circledR}$ assay was used, in order to evaluate the stability of the oils in relation to the autoxidation, by exposing them to oxidizing conditions and measuring the time until the volatile acids were detected (Rancimat induction time). The appearances of these acids were recorded in a measuring instrument, as an increase in conductivity (Méndez et al., 1996). The equipment used was a Metrohm 743 Rancimat (Metrohm Instruments, Herisau, Switzerland), with a software (1.0) control. The oil samples $(5 \mathrm{~g})$ were exposed to an oxidation at $110^{\circ} \mathrm{C}$ (oxygen flow rate of $20 \mathrm{~L} / \mathrm{h}$ ). The induction times (IT) were recorded automatically and they were expressed in hours (h).

\subsection{Statistical analysis}

The quantitative data is presented as mean values, with respective standard deviation values of the three replicates. The analyses were processed by a one-way analysis of variance (ANOVA), followed by Tukey's test, in order to determine the significant differences $(\mathrm{p}<0.05)$. GraphPad Prism 5.0 Software for Windows (San Diego, CA, USA) was used for the statistical tests.

\section{Results and discussion}

\subsection{Chemical compositions}

The fatty acid profiles of the oils were characterized by GC (Table 1). Palmitic (16:0), stearic (18:0), oleic (18:1 $\omega-9)$ and linoleic $(18: 2 \omega-6)$ acids were detected in all of the oils and the levels of PUFA ( $>65 \%)$ were high. The major fatty acids ( $>50 \%)$ that were present in the LSO and in the PSO were $a$-linolenic acid (LnA; C18:3-9c12c15c) and punicic acid (PA; C18:3-9c11t13c), respectively. Regarding the $\mathrm{BSO}$, three fatty acids were present in similar amounts: stearic (C18:0), linoleic (18:2-9c12c) and $\alpha$-eleostearic (EA; 18:3-9c11t13t).

The results for the LSO were in agreement with the literature, which has reported the presence of about $53 \%-60 \%$ of $\operatorname{LnA}$ (Arora and Chaudhary, 2012; Méndez et al., 1996). Rosa et al. (2010) have also shown that LSO had five main fatty acids in its composition: C16:0 (6.45\%), C18:0 (4.35\%), C18:1 $\omega-9$ (18.00\%), C18:2 $\omega-6$ (12.71\%) and C18:3 $\omega-3$ (58.47\%). For the PSO, the profiles of the fatty acids were $6.04 \%$ (saturated), $6.22 \%$ (monounsaturated) and $87.73 \%$ (polyunsaturated), with $57.28 \%$ being PA. Furthermore, other conjugated triene fatty acids were also observed in this oil, but in minor amounts (Parashar et al., 2010; Arora \& Chaudhary, 2012; Verardo et al., 2014), as was also found in the present study. In the case of the BSO, the EA which was present was below the values that have been reported in the literature ( $>45 \%)$ for those oils that were extracted from this seed by physical/chemical methods (Christie et al., 2001; Pal \& Ghosh, 2012; Nyam \& others 2009). However, our findings were in an agreement with Habicht et al. (2011), who evaluated the lipid extracts of six bitter gourd varieties and they found that the amounts of EA varied markedly within the bitter gourd seeds $(4.75 \%$ to $65.89 \%$ of the total lipids; mean $=26.24 \%)$. These authors concluded that in terms of the concentrations of EA and the fatty acid profiles of the bitter gourd seeds, a factor of maturity was more important than the variety. This was because of the proven biological effects of the bitter gourd oil and its high concentration in the seeds. It was concluded that the seeds should not be removed during a food preparation.

Table 1. Fatty acid profiles that were present in the oils, as assessed by GC (\%) and MS [ $\left.\mathrm{M}^{+}\right]$.

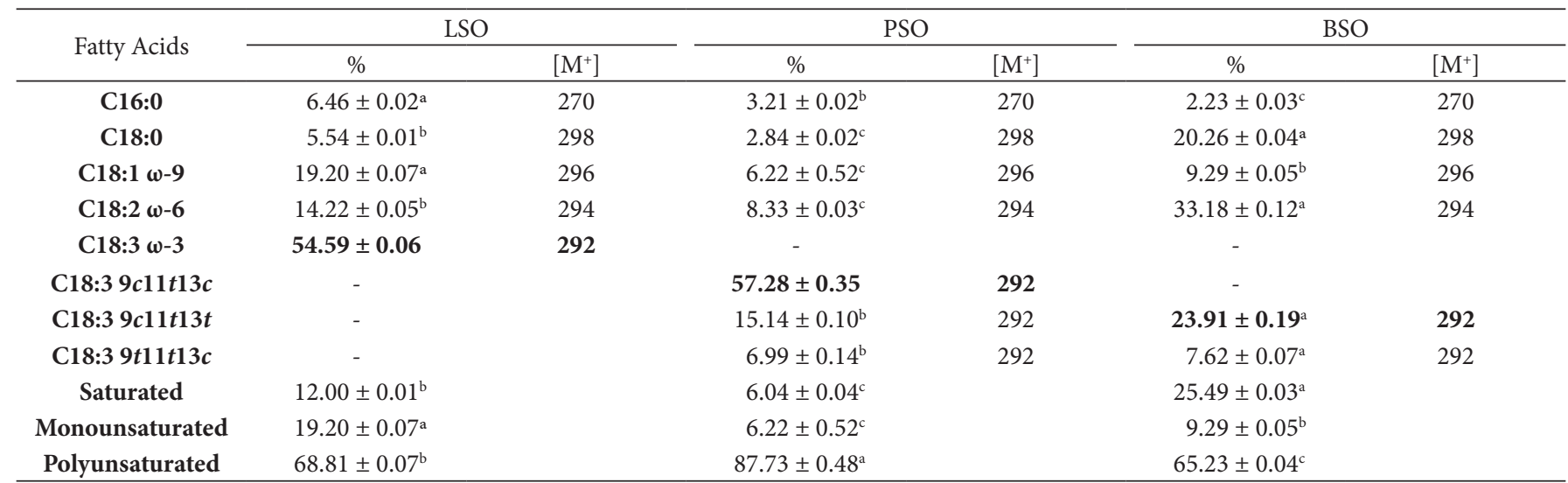

Results are expressed as a mean \pm standard deviation $(\mathrm{n}=3)$; values in the same line with an unlike letter were significantly different $(\mathrm{p}<0.05)$; Legend: GC $=$ gas chromatography, $\mathrm{MS}=$ mass spectrometry, $\left[\mathrm{M}^{+}\right]=$Molecular Ion, $\mathrm{LSO}=$ linseed oil, $\mathrm{PSO}=$ pomegranate seed oil and $\mathrm{BSO}=$ Bitter gourd seed oil. 
The main fatty acids of the oils were confirmed by GC-MS. The differences in the mass spectra between PA and EA could be observed in the fragmentation patterns of the isomer ions at $\mathrm{m} / \mathrm{z} 185$ and 189, respectively (Figure 1). The mass spectrum of PA methyl was in accordance with Topkafa et al. (2015).

The amounts of the relevant compounds, such as the tocopherols in seed oils, are often correlated with the relatively abundant levels of unsaturated fatty acids, which represent a further advantage in terms of their nutraceutical value (Caligiani et al., 2010). As the three oils were rich in unsaturated fatty acids, their tocopherol contents were analyzed (Table 2). This table also presents the phytosterol compositions, which according to Mancini-Filho et al. (2015), are present in all vegetable oils and comprise of the largest portions of the unsaponifiable fraction. The phytosterol profiles were characteristic of each type of oil. Figure 2 shows the samples and the standard chromatograms of the phytosterols and the tocopherols. a

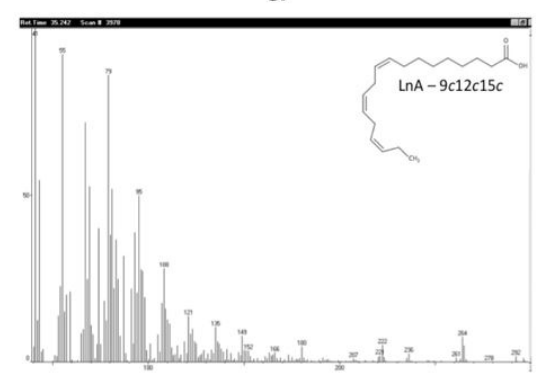

b

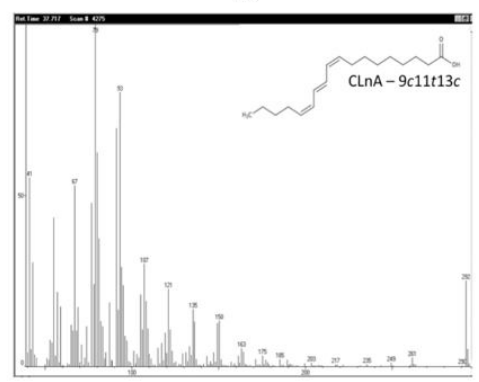

c

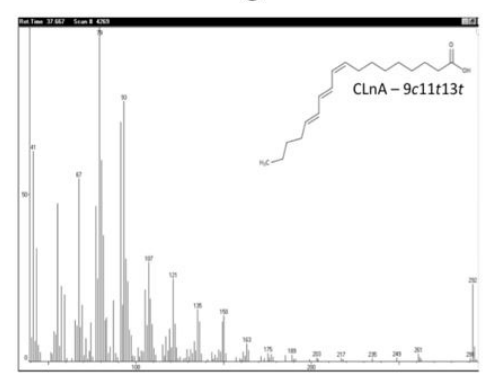

Figure 1. Absorption spectra corresponding to the GC-MS values of the major fatty acids (C18:3) in the oils: LSO-9c12c15c (a), PSO-9c11t13c (b) and BSO-9c11t13t (c).

Table 2. The Phytosterols and the Tocopherols (mg/100g) that were present in the Seed Oils.

\begin{tabular}{|c|c|c|c|c|c|}
\hline & \multicolumn{5}{|c|}{ Phytosterol (mg/100g) } \\
\hline & Campesterol & Stigmasterol & $\beta$-sitosterol & $\mathrm{Ui}$ & Total \\
\hline LSO & $111.9 \pm 2.6^{\mathrm{a}}$ & $8.3 \pm 1.0^{\mathrm{a}}$ & $150.8 \pm 4.0^{c}$ & $210.4 \pm 2.8^{\mathrm{a}}$ & $481.4 \pm 10.5^{\mathrm{b}}$ \\
\hline PSO & $56.3 \pm 2.6^{\mathrm{b}}$ & $3.9 \pm 0.9^{\mathrm{b}}$ & $315.0 \pm 15.8^{\mathrm{b}}$ & $164.9 \pm 34.4^{\mathrm{ab}}$ & $540.1 \pm 53.7^{\mathrm{ab}}$ \\
\hline \multirow[t]{3}{*}{ BSO } & $29.9 \pm 1.1^{\mathrm{c}}$ & $0.5 \pm 0.3^{c}$ & $440.6 \pm 9.3^{\mathrm{a}}$ & $124.0 \pm 9.5^{\mathrm{b}}$ & $595.0 \pm 20.2^{\mathrm{a}}$ \\
\hline & \multicolumn{5}{|c|}{ Tocopherol (mg/100g) } \\
\hline & a-tocopherol & $\beta$-tocopherol & $\gamma$-tocopherol & $\delta$-tocopherol & Total \\
\hline LSO & - & $31.6 \pm 1.9$ & $74.8 \pm 3.4^{c}$ & $1.2 \pm 0.0^{\mathrm{b}}$ & $107.6 \pm 4.6^{c}$ \\
\hline PSO & $8.3 \pm 0.3^{b}$ & - & $335.8 \pm 0.3^{\mathrm{a}}$ & $8.6 \pm 0.6^{\mathrm{a}}$ & $352.7 \pm 1.2^{\mathrm{a}}$ \\
\hline BSO & $20.0 \pm 2.4^{\mathrm{a}}$ & - & $144.6 \pm 24.5^{\mathrm{b}}$ & - & $164.6 \pm 24.4^{\mathrm{b}}$ \\
\hline
\end{tabular}

Results are expressed as a mean \pm standard deviation $(n=3)$; values in the same column with an unlike letter were significantly different $(\mathrm{p}<0.05)$; Legend: Ui $=$ summation of the unidentified peaks, $\mathrm{LSO}=$ linseed oil, $\mathrm{PSO}=$ pomegranate seed oil and BSO = Bitter gourd seed oil.

a
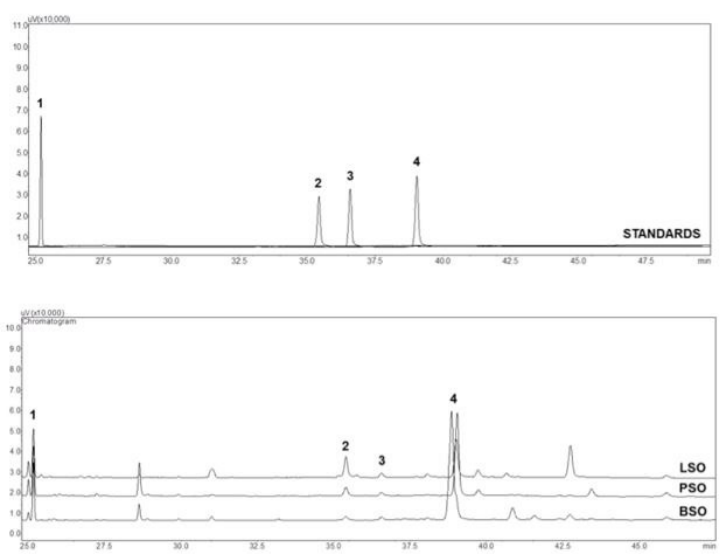

b
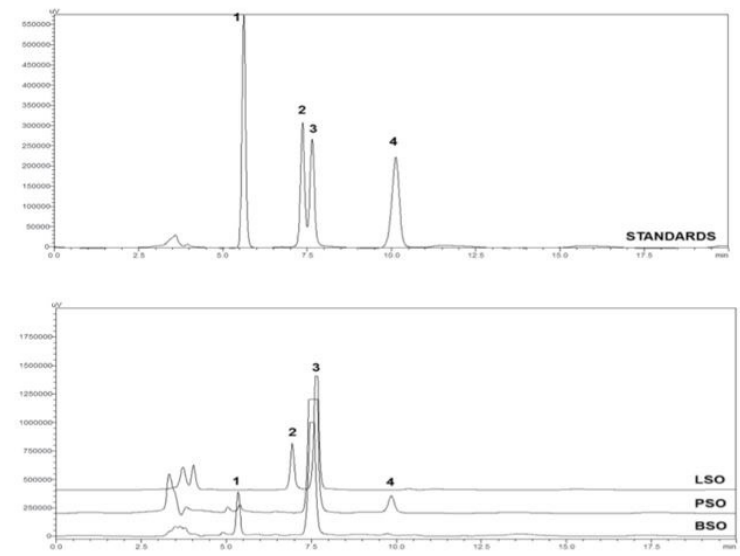

Figure 2. Chromatograms corresponding to the phytosterols, as were assessed by GC (a) and the tocopherols by HPLC (b) of the oils. (Peak Numbers: for the phytosterols (1) $5 \alpha$-cholestane, (2) campesterol, (3) stigmasterol, (4) $\beta$-sitosterol; for the tocopherols (1) $\alpha$-tocopherol, (2) $\beta$-tocopherol, (3) $\gamma$-tocopherol, (4) $\delta$-tocopherol). 
The importance of some plant sterols (sitosterol, campesterol and stigmasterol) in the food industry is that they can be added to industrialized products, which have functional claims due to their cholesterol-lowering effects (Pande \& Akoh, 2009). Table 2 shows that the contents of the total phytosterols did not differ between the PSO and the BSO and that $\beta$-sitosterol was found in the highest concentrations in all of the oils. To be specific, the BSO had a higher $\beta$-sitosterol content, when compared with the PSO, which in turn, was higher than that of the LSO and their compositions were consistent with that which has been observed in the literature (Habicht et al., 2011; Caligiani et al., 2010; Pande \& Akoh, 2009).

Regarding the contents of vitamin E, it was seen that the PSO had approximately 300\% more tocopherol content, when compared with the LSO and $200 \%$ more than the BSO (Table 2). All of the oils showed a predominance of the $\gamma$-tocopherol isomer, which has been referred to by Habibnia et al. (2012) as a potent antioxidant. Some studies have indicated a prevalence of the a-tocopherol isomer in PSO and BSO (Anjum et al., 2013; Nyam et al., 2009; Caligiani et al., 2010). According to Verardo et al. (2014), the total tocopherol contents of the pomegranate seeds from different cultivars ranged from 68 and $263 \mathrm{mg} / 100 \mathrm{~g}$ of oil, with $\gamma$-tocopherol representing $88 \%-95 \%$ of the total tocopherols in the PSO. Jing et al. (2012) studied four pomegranate seed cultivars from Shaanxi Province (China) and they found that the contents of the tocopherols in the form of $\gamma$-tocopherol were twice that of $a$-tocopherol. They also found that the total tocopherols ranged from 219 - $495 \mathrm{mg} / 100 \mathrm{~g}$ oil, but the carotenoids were not detected in any of their samples. The present study has evaluated the contents of the total carotenoids in the oils and unlike the total tocopherol contents, the PSO $(0.9 \pm 0.0 \mu \mathrm{g} / \mathrm{g})$ presented a low value, followed by the LSO $(8.4 \pm 0.2 \mu \mathrm{g} / \mathrm{g})$, with the highest amount being found in the BSO $(14.8 \pm 0.3 \mu \mathrm{g} / \mathrm{g})$, with all of them being statistically different.

According to Chirinos et al. (2013), numerous health benefits have been attributed to the phytosterols, the tocopherols and the carotenoids. The phytosterols have been reported to reduce blood cholesterol and to decrease the risk of certain types of cancer. The tocopherols have vitamin E properties and they display strong antioxidant activities, conferring a protection against lipid peroxidation in the biological tissues and in foods. The carotenoids are considered to promote human health, because they are responsible for critical biological functions.

\subsection{Antioxidant capacities}

Figure 3 shows the graphs that were related to the antioxidant activities of the oils by the four different models. The rates of reduction in the absorbance of $\beta$-carotene in the presence of the studied oils (LSO, PSO and BSO) and the synthetic antioxidant BHT, all at a concentration of $0.35 \mathrm{mg} / \mathrm{mL}$, are presented in Figure 3a. After 120 minutes, the percentages of antioxidant protection in the control (blank) were 31\% (LSO), 22\% (PSO) and $23 \%$ (BSO), without a significant difference between them. When using the same methodology, Schubert et al. (1999) reported a higher percentage (approximately 40\%) for the cold-pressed PSO, which was close to that observed for green tea.
The aforementioned researchers attributed its high antioxidant activities to both the fatty acid compositions and the presence of the flavonoids. The $\beta$-carotene bleaching method was important, in order to evaluate its role in protecting $\beta$-carotene from oxidation. This was because in the absence of antioxidants, the oxidation products (lipid hydroperoxides, conjugated dienes and the volatile by-products) of linoleic acid simultaneously attacked $\beta$-carotene, resulting in the bleaching of its characteristic color (Hennessy et al., 2011).

Unlike the $\beta$-carotene oxidation, the DPPH• and the ABTS- scavenging results showed that the PSO had the highest antioxidant activities, with significant differences at concentrations of 5 and $10 \mathrm{mg} / \mathrm{mL}$ and, therefore, it had a lower EC50 (8.8 and $5.9 \mathrm{mg} / \mathrm{mL}$, respectively), followed by the BSO (12 and $13 \mathrm{mg} / \mathrm{mL}$, respectively) and finally the LSO (18 and $30 \mathrm{mg} / \mathrm{mL}$, respectively). The results of the DPPH • method are shown in Figure $3 \mathrm{~b}$ and the ABTS• method is shown in Figure $3 \mathrm{~d}$. At a concentration of $10 \mathrm{mg} / \mathrm{mL}$, the $\mathrm{PSO}$ reduced more than $50 \%$, both by the DPPH• test and by the ABTS• test. The effects of the antioxidants on the DPPH and the ABTS methods were thought to be due to the hydrogen donating activities.

The antioxidant capacities of the PSO $(\mathrm{EC} 50=22 \mathrm{mg} / \mathrm{mL})$ were significantly lower in the ORAC system, when compared to the other oils, with the BSO having higher antioxidant activities, but with a lower EC50 (5.9 mg/mL) (Figure 3c). The EC50 value was the required initial concentration of a selected antioxidant sample, in order to quench $50 \%$ of the free radicals in the reaction system; therefore, a lower EC50 value corresponded to a stronger antioxidant activity in a tested sample (Saha et al., 2012).

The literature contains different results regarding the antioxidant activities of the studied oils. According to Sielicka et al. (2014), $74 \%-76 \%$ of DPPH was left after a 10 min incubation with a non-polar fraction of linseed oil, in a concentration of $400 \mathrm{mg} / \mathrm{mL}$. As for PA and EA, the results of the antioxidant activities when using the DPPH method were up around $50 \%$ and 53\%, respectively, both when at a concentration of $250 \mu \mathrm{g} / \mathrm{mL}$ (Lucci et al., 2015). For Tunisian pomegranate seed extracts (methanol), Mekni et al. (2014) showed an ability to scavenge the ABTS•, which ranged from $58 \%$ to $66 \%$, while for DPPH•, it ranged from $34 \%$ to $39 \%$. In addition, these latter authors found a significant correlation (0.582, p<0.05) between the DPPH and the ABTS analytical methods, when determining the antioxidant powers of pomegranate seeds. Anjum [16] related a strong DPPH• scavenging activity $(\mathrm{EC} 50=144$ and $157 \mathrm{mg} / \mathrm{mL}$ ) for two bitter gourd seed extracts (ethanol) from Pakistan, with EC50 values higher than those found in the present study.

The CLnA compounds were characterized by a hydroxyl radical scavenging activity and for reducing properties, especially when in their trans isomer form (Hennessy et al., 2011; Carvalho et al., 2010; Lucci et al.,2015). According to Saha et al. (2012), due to the high trans content of a-eleostearic acid, it possesses a higher stability and antioxidant activity. However, in this study, the researchers found a higher antioxidant activity for the BSO only, when using the ORAC method. Interestingly enough, the role of the unsaturated fatty acids in these processes leads to a controversy, since opposing results concerning their protective 


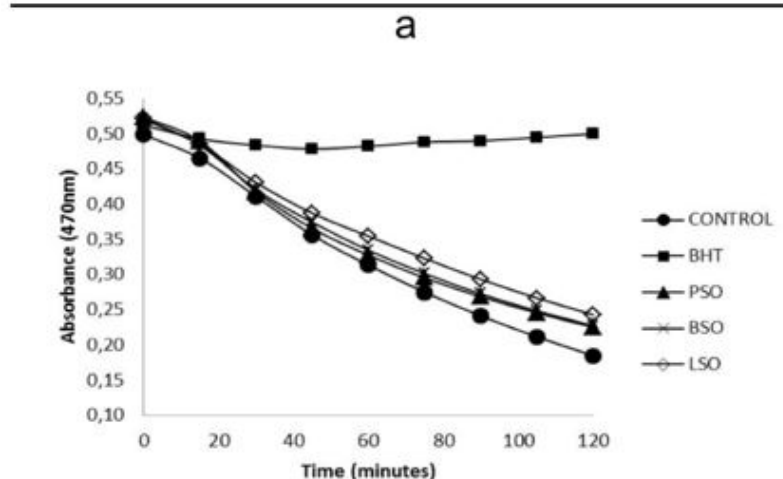

C

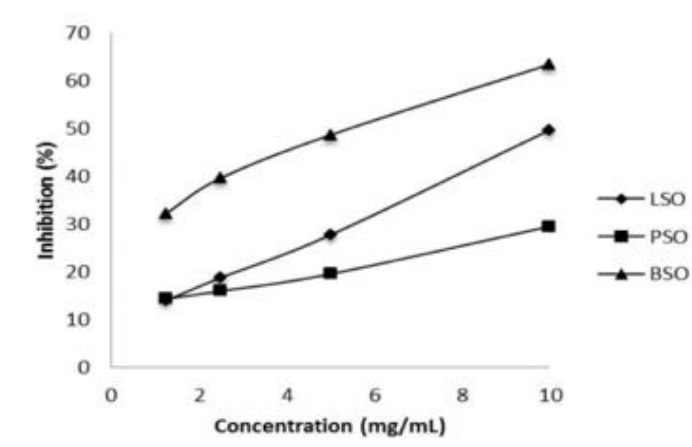

b

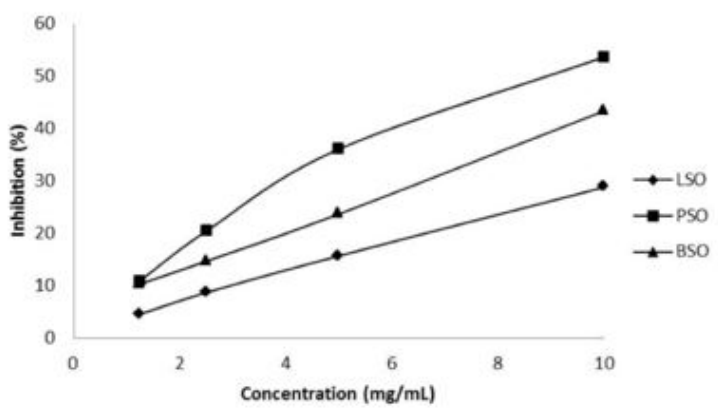

d

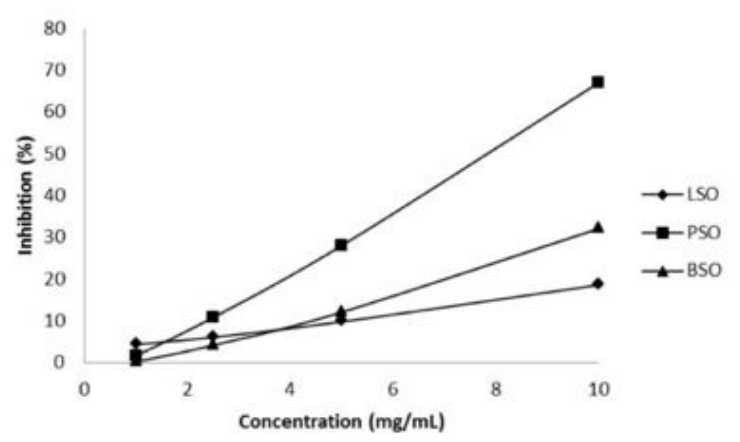

\begin{tabular}{cccc}
\hline \multirow{2}{*}{ Samples } & \multicolumn{2}{c}{ EC50 value } \\
\cline { 2 - 4 } & ORAC & DPPH• & ABTS \\
\hline LSO $(\mathrm{mg} / \mathrm{mL})$ & 10.2 & 17.7 & 29.7 \\
PSO $(\mathrm{mg} / \mathrm{mL})$ & 22.0 & 8.8 & 5.9 \\
BSO $(\mathrm{mg} / \mathrm{mL})$ & 5.9 & 11.8 & 12.7 \\
\hline SA $(\mu \mathrm{g} / \mathrm{mL})$ & 1.29 & 350 & 41.9 \\
\hline
\end{tabular}

Figure 3. Antioxidant capacities by kinetics of the inhibition of the oxidation of $\beta$-carotene (a), DPPH• scavenging capacity (b), oxygen radical absorbance capacity - ORAC (c) and ABTS• scavenging capacity (d) of the models. The table also presents the EC50 values, where SA= the synthetic antioxidant (Trolox or BHT).

or pro-oxidant effects have been observed by different authors (Mekni et al., 2014; Habibnia et al., 2012).

When considering that different antioxidant compounds may act in vivo through different mechanisms of action, no single method can fully evaluate the antioxidant capacities of foods (Lucci et al., 2015). Moreover, the literature contains several examples of methods for preparing samples, sometimes choosing the end-point of an assay and then expressing the results. Diverse antioxidant extraction conditions, such as the solvent and the temperature selections, are described in the literature, even for the same method. For these reasons, it is difficult to compare the results of studies that have been carried out in different laboratories (Sielicka et al., 2014; Chirinos et al., 2013). Consequently, it is recommended that the antioxidant capacity values should only be compared, when the method is the same and of the same mode. It has become very important to apply more than two methodologies, in order to evaluate these antioxidant activities.

\subsection{Quality and stability parameters}

The determinations that are made in the analyses of oils and fats are usually the so-called indexes, which are the expressions of their physical or chemical properties and not the percentages of their constituents. Table 3 shows some indexes that were analyzed in the oil samples.

According to the quality requirements as recommended by the Codex Alimentarius Commission (1999), cold-pressed oils should have a maximum of $4.0 \mathrm{mg} / \mathrm{g}$ of acidity and $15 \mathrm{mEq} / \mathrm{kg}$ of peroxide values. The results for LSO and PSO were within 
Table 3. The Quality and the Stability Parameters of the 3 Seed Oils.

\begin{tabular}{ccccc}
\hline & $\mathrm{Av}(\mathrm{mg} / \mathrm{g})$ & $\mathrm{Pv}(\mathrm{mEq} / \mathrm{Kg})$ & $\mathrm{TBAv}(\mu \mathrm{g} / \mathrm{g})$ & $\mathrm{Rancimat}^{\circledR}(\mathrm{IT}=\mathrm{h})$ \\
\hline LSO & $0.84 \pm 0.00^{\mathrm{b}}$ & $6.46 \pm 0.59^{\mathrm{b}}$ & $0.29 \pm 0.03^{\mathrm{a}}$ & $1.66 \pm 0.01^{\mathrm{a}}$ \\
PSO & $0.83 \pm 0.00^{\mathrm{b}}$ & $5.43 \pm 0.59^{\mathrm{b}}$ & $0.17 \pm 0.02^{\mathrm{b}}$ & $0.63 \pm 0.08^{\mathrm{b}}$ \\
BSO & $4.35 \pm 0.05^{\mathrm{a}}$ & $16.42 \pm 1.08^{\mathrm{a}}$ & $0.10 \pm 0.00^{\mathrm{c}}$ & $0.27 \pm 0.01^{\mathrm{c}}$ \\
\hline
\end{tabular}

Results are expressed as a mean \pm standard deviation $(n=3)$; values in the same column with an unlike letter were significantly different $(\mathrm{p}<0.05) ;$ Legend: Av $=$ acidity value, $\mathrm{Pv}=$ peroxide value (the results are reported in milliequivalents of oxygen per kilogram of oil), TBAv $=2$-thiobarbituric acid value, IT $=$ induction times, $\mathrm{LSO}=$ linseed oil, PSO $=$ pomegranate seed oil and $\mathrm{BSO}=$ Bitter gourd seed oil.

the standardized requirements (Table 3 ) and the values for PSO were lower than they were for LSO. Khoddami et al. (2014) found peroxide values of $4.67 \mathrm{mEq} / \mathrm{kg}$ in Iranian pomegranate seed oil that was extracted by cold pressing. With respect to the BSO, the values that were obtained for acidity and peroxide, significantly differed from the other two oils and they were slightly above the recommended requirements. Sielicka et al. (2014) noted that peroxide values were one of the most commonly used tests for evaluating the oxidative rancidity in oils and fats. They measured the concentrations of the peroxides and the hydroperoxides, when they were formed in the initial stages of lipid oxidation.

The thiobarbituric acid reactive substances can also be measured as products of the decompositions of lipid peroxide. The TBARs values were the highest for LSO, which may have been associated with its high content of $\alpha$-linolenic acid (55\%), because the presence of two methylene carbons, makes the oxidation of the molecules more likely. While the principal components of PSO and BSO are fatty acids, they do not contain methylene groups between their double bonds.

The Rancimat ${ }^{\circledR}$ system showed oxidative stabilities in the following decreasing order - $\mathrm{LSO}>\mathrm{PSO}>\mathrm{BSO}$ - as shown by the induction times in Table 3. Therefore, LSO (which is rich in unconjugated fatty acids) had the highest oxidative stability of the three oils that were studied, while BSO showed the lowest stability. This was in accordance with the high acidity and peroxide values that were found. According to Habibnia et al. (2012), the induction periods of the oils that were extracted from different varieties of pomegranate seeds at $110^{\circ} \mathrm{C}$, when using the Rancimat ${ }^{\circledR}$ model, ranged from 0.73 to 1.02 hours. These authors related that the induction periods of the studied oils were shorter than those for other edible oils, due to a high concentration of punicic acid. Therefore, any extracted oils should be kept in a dry cold place, away from light, as well as being stored in closed containers.

Some authors have related that a presence of the CLnAs can contribute to the oxidative deterioration of vegetable oils, thus, affecting their stability (Khoddami et al., 2014; Habibnia et al., 2012). Yang et al. (2009) compared the oxidative stability of individual CLnA isomers and of LnA, its corresponding non-conjugated acid, by oxidizing both of them in air at $50^{\circ} \mathrm{C}$ and monitoring their reactions by using gas chromatography and the oxygen consumption test. They observed that the CLnAs were more susceptible to autoxidation than were the LnA. Among the three groups of isomers of the CLnAs, the $t, t, t$-CLnA isomers showed the greatest stability, followed by the $c, t, t-C \operatorname{Ln} \mathrm{A}$ isomers and the $c, t, c$-CLnA isomers. However, in the present study, the oils containing the $c, t, c$-CLnA isomer
(PSO) presented a better stability, when compared to the $c, t, t$ CLnA isomer (BSO). The higher amount of tocopherols may be a possible explanation for this, because the tocopherols are considered to be the most important natural antioxidants in oils.

\section{Conclusions}

Differences in the compositions of the fatty acids, as well as different bioactive compounds and unalike antioxidant capacities, were observed in the two seed oils (pomegranate and bitter gourd) that were assessed. Important contents of conjugated $\alpha$-linolenic acid were found in the pomegranate and bitter gourd seed oils, as well as phytosterols (mainly $\beta$-sitosterol) and tocopherols (mainly $\gamma$-tocopherol). All of the samples showed varied antioxidant capacities, depending upon the seed's origin and the method that was used for extraction. In general, the highest phytochemical contents and the greatest in vitro antioxidant capacities were exhibited by the pomegranate seed oil, when using both of the DPPH and ABTS methods.

Pomegranate and bitter gourd seed oils, which are by-products from their processing and extraction, are important and alternative sources of polyunsaturated fatty acids. They displayed conjugated double bonds and other bioactive compounds. Thus, new research studies by this current group will be focused on the potential beneficial physiological activities of these oils.

\section{Acknowledgements}

The authors would like to thank the São Paulo State Research Foundation (FAPESP, Process 2013/24490-7) for funding the research and the National Council of Technological and Scientific Development (CNPq, Process 152926/2015-1 and $168115 / 2014-0)$, for the scholarship that was granted.

\section{References}

Almeida, C. A. S. (2009). Avaliação dos principais fitosteróis em óleos vegetais e azeite (Dissertation). Universidade Estadual de Campinas, Campinas.

American Oil Chemists' Society - AOCS. (2004). Official methods and recommended practices of the american oil chemists' society (5th ed.). Champaign: AOCS.

Anjum, F., Shahid, M., Bukhari, S. A., Anwar, S., \& Latif, S. (2013). Study of quality characteristics and efficacy of extraction solvent / technique on the antioxidant activity of bitter gourd seed. Food Processing \& Technology, 4, 2-9.

Arora, A., \& Chaudhary, S. (2012). Potential source of $\alpha$ - eleostearic acid from Momordica charantia seed oil of arid zone plants in 
Rajasthan, India. International Journal of Basic and Applied Chemical Sciences, 2, 59-62.

Aruna, P., Venkataramanamma, D., Singh, A. K., \& Singh, R. P. (2016). Health benefits of punicic acid: a review. Comprehensive Reviews in Food Science and Food Safety, 15(1), 16-27. http://dx.doi. org/10.1111/1541-4337.12171.

Baublits, R. T., Pohlman, F. W., Brown, H. Jr, Johnson, Z. B., Proctor, A., Sawyer, J., Dias-Morse, P., \& Galloway, D. L. (2007). Injection of conjugated linoleic acid into beef strip loins. Meat Science, 75(1), 8493. http://dx.doi.org/10.1016/j.meatsci.2006.07.006. PMid:22063415.

Blois, M. S. (1958). Antioxidant determination by the use of a stable free radical. Nature, 181(4617), 1199-1200. http://dx.doi. org/10.1038/1811199a0.

Caligiani, A., Bonzanini, F., Palla, G., Cirlini, M., \& Bruni, R. (2010). Characterization of a potential nutraceutical ingredient: pomegranate (Punica granatum L.) seed oil unsaponifiable fraction. Plant Foods for Human Nutrition (Dordrecht, Netherlands), 65(3), 277-283. http:// dx.doi.org/10.1007/s11130-010-0173-5. PMid:20607413.

Carvalho, E. B. T., Melo, I. L. P., \& Mancini-Filho, J. (2010). Chemical and physiological aspects of isomers of conjugated fatty acids. Food Science and Technology (Campinas), 30(2), 295-307. http://dx.doi. org/10.1590/S0101-20612010000200002.

Chirinos, R., Zuloeta, G., Pedreschi, R., Mignolet, E., Larondelle, Y., \& Campos, D. (2013). Sacha inchi (Plukenetia volubilis): A seed source of polyunsaturated fatty acids, tocopherols, phytosterols, phenolic compounds and antioxidant capacity. Food Chemistry, 141(3), 1732-1739. http://dx.doi.org/10.1016/j.foodchem.2013.04.078. PMid:23870885.

Christie, W. W., Sébédio, J. L., \& Juanéda, P. (2001). A practical guide to the analysis of conjugated linoleic acid. Inform (Silver Spring, Md.), 12, 147-152.

Codex Alimentarius Commission - CODEX. (1999). Codex stan 210-1999: codex standard for named vegetable oils. Retrieved from: http://www.codexalimentarius.org/input/download/standards/336/ CXS_210e.pdf

Fernandes, L., Pereira, J. A., Lopéz-Cortés, I., Salazar, D. M., Ramalhosa, E., \& Casal, S. (2015). Fatty acid, vitamin E and sterols composition of seed oils from nine different pomegranate (Punica granatum L.) cultivars grown in Spain. Journal of Food Composition and Analysis, 39, 13-22. http://dx.doi.org/10.1016/j.jfca.2014.11.006.

Habibnia, M., Ghavami, M., Ansaripour, M., \& Vosough, S. (2012). Chemical evaluation of oils extracted from five different varieties of Iranian pomegranate seeds. Journal of Food Biosciences and Technology, 2, 35-49.

Habicht, S. D., Kind, V., Rudloff, S., Borsch, C., Mueller, A. S., Pallauf, J., Yang, R., \& Krawinkel, M. B. (2011). Quantification of anti-diabetic extracts and compounds in bitter gourd varieties. Food Chemistry, 126(1), 172-176. http://dx.doi.org/10.1016/j.foodchem.2010.10.094.

Hennessy, A., Ross, R. P., Devery, R., \& Stanton, C. (2011). The health promoting properties of the conjugated isomers of $\alpha$-linolenic acid. Lipids, 46(2), 105-119. http://dx.doi.org/10.1007/s11745-010-35015. PMid:21161605.

Jing, P., Ye, T., Shi, H., Sheng, Y., Slavin, M., Gao, B., Liu, L., \& Yu, L. (2012). Antioxidant properties and phytochemical composition of China-grown pomegranate seeds. Food Chemistry, 132(3), 1457-1464. http://dx.doi.org/10.1016/j.foodchem.2011.12.002. PMid:29243636.

Khoddami, A., Man, Y. B. C., \& Roberts, T. H. (2014). Physico-chemical properties and fatty acid profile of seed oils from pomegranate (Punica granatum L.) extracted by cold pressing. European Journal of Lipid Science and Technology, 116(5), 553-562. http://dx.doi. org/10.1002/ejlt.201300416.

Lucci, P., Pacetti, D., Loizzo, M. R., \& Frega, N. G. (2015). Punica granatum cv. Dente di Cavallo seed ethanolic extract: antioxidant and antiproliferative activities. Food Chemistry, 167, 475-483. http:// dx.doi.org/10.1016/j.foodchem.2014.06.123. PMid:25149014.

Mancini-Filho, J., Takemoto, E., \& Aued-Pimentel, S. (2015). Parâmetros de identidade e qualidade de óleos e gorduras. In: L. B. AlmeidaMuradian \& M. D. V. C. Penteado (Eds.), Ciências farmacêuticas - vigilância sanitária - tópicos sobre legislação e análise de alimentos (2nd ed., chap. 6, pp. 63-82). Rio de Janeiro: Guaranbara Koogan.

Mekni, M., Dhibi, M., Kharroubi, W., \& Hmida, R. B. (2014). Natural conjugated and trans fatty acids in seed oils and phytochemicals in seed extracts issued from three Tunisian pomegranate (Punica granatum L.) cultivars. International Journal of Current Microbiology and Applied Sciences, 3(8), 778-792.

Melo, I. L. P., Carvalho, E. B. T., \& Mancini-Filho, J. (2014). Pomegranate seed oil (Punica granatum L.): a source of punicic acid (conjugated a-linolenic acid). Journal of Human Nutrition \& Food Science, 2, 1-11.

Méndez, E., Sanhueza, J., Speisky, H., \& Valenzuela, A. (1996). Validation of the Rancimat test for the assessment of the relative stability of fish oils. Journal of the American Oil Chemists' Society, 73(8), 1033-1037. http://dx.doi.org/10.1007/BF02523412.

Nenadis, N., Wang, L. F., Tsimidou, M., \& Zhang, H. Y. (2004). Estimation of scavenging activity of phenolic compounds using the ABTS •+ assay. Journal of Agricultural and Food Chemistry, 52(15), 4669-4674. http://dx.doi.org/10.1021/jf0400056. PMid:15264898.

Nyam, K. L., Tan, C. P., Lai, O. M., Long, K., \& Man, Y. B. C. (2009). Physicochemical properties and bioactive compounds of selected seed oils. Lebensmittel-Wissenschaft + Technologie, 42(8), 1396-1403. http://dx.doi.org/10.1016/j.lwt.2009.03.006.

Pal, M., \& Ghosh, M. (2012). Studies on comparative efficacy of $\alpha$-linolenic acid and $\alpha$-eleostearic acid on prevention of organic mercury-induced oxidative stress in kidney and liver of rat. Food and Chemical Toxicology, 50(3-4), 1066-1072. http://dx.doi.org/10.1016/j. fct.2011.12.042. PMid:22269903.

Pande, G., \& Akoh, C. C. (2009). Antioxidant capacity and lipid characterization of six Georgia-grown pomegranate cultivars. Journal of Agricultural and Food Chemistry, 57(20), 9427-9436. http://dx.doi. org/10.1021/jf901880p. PMid:19743855.

Parashar, A., Sinha, N., \& Singh, P. (2010). Lipid contents and fatty acids composition of seed oil from twenty five pomegranates varieties grown in India. Advance Journal of Food Science and Technology, 2, 12-15.

Prescha, A., Grajzer, M., Dedyk, M., \& Grajeta, H. (2014). The Antioxidant Activity and Oxidative Stability of Cold-Pressed Oils. Journal of the American Oil Chemists' Society, 91(8), 1291-1301. http://dx.doi. org/10.1007/s11746-014-2479-1. PMid:25076788.

Prior, R. L., Hoang, H., Gu, L., Wu, X., Bacchiocca, M., Howard, L., Hampsch-Woodill, M., Huang, D., Ou, B., \& Jacob, R. (2003). Assays for hydrophilic and lipophilic antioxidant capacity (oxygen radical absorbance capacity (ORACFL)) of plasma and other biological and food samples. Journal of Agricultural and Food Chemistry, 51(11), 3273-3279. http://dx.doi.org/10.1021/jf0262256. PMid:12744654.

Ribeiro, M. C., Vilas Boas, E. V. B., Riul, T. R., Pantoja, L., Marinho, H. A., \& Santos, A. S. (2012). Influence of the extraction method and storage time on the physicochemical properties and carotenoid levels of pequi (Caryocar brasiliense Camb.) oil. Food Science and Technology (Campinas), 32(2), 386-392. http://dx.doi.org/10.1590/ S0101-20612012005000053. 
Rosa, D. D., Sales, R. L., Moraes, L. F. D. S., Lourenço, F. C., Neves, C. A., Sabarense, C. M., Ribeiro, S. M. R., \& Peluzio, M. D. C. G. (2010). Flaxseed, olive and fish oil influence plasmatic lipids, lymphocyte migration and morphometry of the intestinal of Wistar rats. Acta Cirurgica Brasileira, 25(3), 275-280. http://dx.doi.org/10.1590/ S0102-86502010000300010. PMid:20498941.

Saha, S. S., Patra, M., \& Ghosh, M. (2012). In vitro antioxidant study of vegetable oils containing conjugated linolenic acid isomers. Lebensmittel-Wissenschaft + Technologie, 46(1), 10-15. http://dx.doi. org/10.1016/j.lwt.2011.11.008.

Schubert, S. Y., Lansky, E. P., \& Neeman, I. (1999). Antioxidant and eicosanoid enzyme inhibition properties of pomegranate seed oil and fermented juice flavonoids. Journal of Ethnopharmacology, 66(1), 11-17. http://dx.doi.org/10.1016/S0378-8741(98)00222-0. PMid:10432202.

Sielicka, M., Małecka, M., \& Purłan, M. (2014). Comparison of the antioxidant capacity of lipid-soluble compounds in selected coldpressed oils using photochemiluminescence assay (PCL) and DPPH method. European Journal of Lipid Science and Technology, 116(4), 388-394. http://dx.doi.org/10.1002/ejlt.201300356.

Topkafa, M., Kara, H., \& Sherazi, S. T. H. (2015). Evaluation of the Triglyceride Composition of Pomegranate Seed Oil by RP-HPLC Followed by GC-MS. Journal of the American Oil Chemists' Society, 92(6), 791-800. http://dx.doi.org/10.1007/s11746-015-2652-1.

Verardo, V., Garcia-Salas, P., Baldi, E., Segura-Carretero, A., FernandezGutierrez, A., \& Caboni, M. F. (2014). Pomegranate seeds as a source of nutraceutical oil naturally rich in bioactive lipids. Food Research International, 65, 445-452. http://dx.doi.org/10.1016/j. foodres.2014.04.044.

Yang, L., Cao, Y., Chen, J. N., \& Chen, Z. Y. (2009). Oxidative stability of conjugated linolenic acids. Journal of Agricultural and Food Chemistry, 57(10), 4212-4217. http://dx.doi.org/10.1021/jf900657f. PMid:19368396.

Yuan, G.F., Chen, X.-E., \& Li, D. (2014). Conjugated linolenic acids and their bioactivities: a review. Food \& Function, 5(7), 1360-1368. http://dx.doi.org/10.1039/c4fo00037d. PMid:24760201. 